\title{
Accurate Base Composition of Double-Strand DNA by Mass Spectrometry
}

\author{
David J. Aaserud, Neil L. Kelleher, Daniel P. Little, and Fred W. \\ McLafferty \\ Baker Chemistry Laboratory, Cornell University, Ithaca, New York, USA
}

An accurate molecular weight $\left(M_{r}\right)$ assignment for a double-strand (ds) DNA determines or greatly restricts the possible number of each of its four bases, while the compositions for its two single-strand (ss) components can also be derived from their $M_{r}$ values. For a ds 64-mer $(39 \mathrm{kDa})$, the $s s-M_{r}$ values $( \pm 0.5 \mathrm{Da})$ of its high-resolution mass spectrum from an electrospray ionization/Fourier transform instrument yield only the correct ds- and ss-base compositions. Literature mass spectra of lower mass accuracy show that such data can also restrict their possible composition assignments, with further discrimination using the abundance vs. base composition of small fragment ions from the dissociation of the ss molecular ions. (c) 1996 American Society for Mass Spectrometry (J Am Soc Mass Spectrom 1996, 7, 1266-1269)

\section{A} ccurate, fast characterization of nucleotides is increasingly important in many research fields, and mass spectrometry (MS) has recently shown high promise for this [1-10]. McCloskey et al. [2] have pointed out that an accurate value of molecular weight $\left(M_{r}\right)$ for an unknown single-strand (ss) oligonucleotide greatly restricts its possible base compositions, the number of each of its four constituent bases. However, the required mass accuracy increases rapidly with increasing $M_{r}$, with \pm 0.5 Da accuracy giving 20 possible DNA compositions for $M_{r}=7584$ Da [7]. Routine measurements [11] with combined electrospray ionization [12] (ESI)/Fourier transform (FT) MS [13] have achieved mass errors of $<0.5 \mathrm{Da}$ for up to $43 \mathrm{kDa} M_{r}$ values [7, 9-11, 14-16] (e.g., 0.2 Da for a $15 \mathrm{kDa}$ DNA [9] and $25 \mathrm{kDa}$ tRNA [10], 0.3 Da for a $31 \mathrm{kDa} 100$-mer DNA) [10]. Recently ESI/MS has been applied to double-strand (ds) DNA from polymerase chain reactions $[5,6]$, with complementary ss 49-mers measured with 0.7 and $0.8 \mathrm{Da}$ errors [5]. We show here that such accuracy will define or greatly restrict the base pair composition of dsDNA as large as $370 \mathrm{kDa}$ (600 base pairs). Furthermore, such accuracy for a $39 \mathrm{kDa}$ dsDNA [17] will define also the base compositions of each of its Watson-Crick complementary ssDNAs.

The negative ion ESI/FTMS spectrum of this dsDNA of two 64-mer ss monomers [17] (Figure 1) yields ${ }_{\mathrm{ss}} M_{r}$ values $[9,10]$ in error by $<0.1 \mathrm{Da}$, as is their sum, the ${ }_{d s} M_{r}$ value, 39,423.6-18 [20]. The accuracy of measuring the ds molecular ion is only \pm 1 Da because

Address correspondence to Dr. Fred W. McLafferty, Baker Chemical Laboratory, Comell University, Department of Chemistry, Ithaca, NY 14853-1301. of the greater uncertainty in fitting the isotopic abundances to the predicted distribution [21]. The monoisotopic $M_{r}$ value $\left(M_{r 0}\right)$ [20] of a ssDNA $\left(\mathrm{A}_{\mathrm{a}} \mathrm{T}_{\mathrm{t}} \mathrm{C}_{\mathrm{c}} \mathrm{G}_{\mathrm{g}}\right)$ is the sum of all its base unit masses (base + sugar + phosphate: $\mathbf{A}=313.0576, \mathrm{~T}=304.0460, \mathrm{C}=289.0463$, and $\mathbf{G}=329.0525)[7,9]$ plus $\mathrm{H}(1.008 \mathrm{Da})$ added at the $5^{\prime}$-terminus, minus $\mathrm{PO}_{2}(62.964 \mathrm{Da})$ missing at the 3 '-terminus, or $\mathrm{aA}+\mathrm{tT}+\mathrm{cC}+\mathrm{gG}-61.956$. For dsDNA $(\mathrm{a}=\mathrm{t}, \mathrm{c}=\mathrm{g}),{ }_{d s} M_{r 0}=\mathrm{a}(\mathbf{A}+\mathrm{T})+\mathrm{c}(\mathrm{C}+\mathrm{G})-$ 123.912; combining these values gives an expression for the number of base pairs, $a+c$, in dsDNA (eq 1).

$$
\mathrm{a}+\mathrm{c}=\left({ }_{d s} M_{r 0}-0.9952 c+123.91\right) / 617.1036
$$

Because the base pair mass values are so similar, with $(\mathbf{C}+\mathbf{G})=(\mathbf{A}+\mathbf{T})+0.9952 \mathrm{Da},{ }_{\mathrm{ds}} M_{\mathrm{ro}}$ depends mainly on the number of pairs and only marginally $(0.9952 \mathrm{c}$ ) on their identity. For the dsDNAs (AT) 600 and (CG) ${ }_{600}, M_{r 0}=370,138$ and 370,735 , respectively; any ${ }_{\text {ds }} M_{r 0}$ value between these also must represent a 600 base pair DNA, as $(\mathrm{CG})_{599}=370,117$ and $(\mathrm{AT})_{601}=$ 370,755 .

Furthermore, a ${ }_{d s} M_{r 0}$ value of $\pm 1 \mathrm{Da}$ accuracy defines the pairs composition to one $c$ value, e.g., the $M_{r 0}$ values of $(\mathrm{AT})_{599}(\mathrm{CG})_{1}=370,139,(\mathrm{AT})_{598}(\mathrm{CG})_{2}=$ 370,140 , etc. Using the Figure 1 measured value of ${ }_{\text {ds }} M_{r 0}=39,405.59$ (from $39,423.65-18-18 \times 1.0034$ ) [20] and eq 1, a + c $=64.0565$; of these 64 base pairs, $35(0.0565 \times 617.1 / 0.9952=35.04)$ must be CG pairs. A measurement error, $\Delta_{\mathrm{ds}} M_{\mathrm{r} 0}$, of $+(-) 0.9952 \mathrm{Da}$ can only lead to $a+(-) 1$ error in the calculated $c$ value, but (if $a+c=<600$ ) will give no base pair error, $\Delta(\mathrm{a}+\mathrm{c})=0$. Thus $\Delta \mathrm{c}=-\Delta \mathrm{a}=\Delta_{\mathrm{ds}} M_{\mathrm{r}} / 0.9952$ (note that $\Delta M_{r 0}=\Delta M_{r}$ ). 


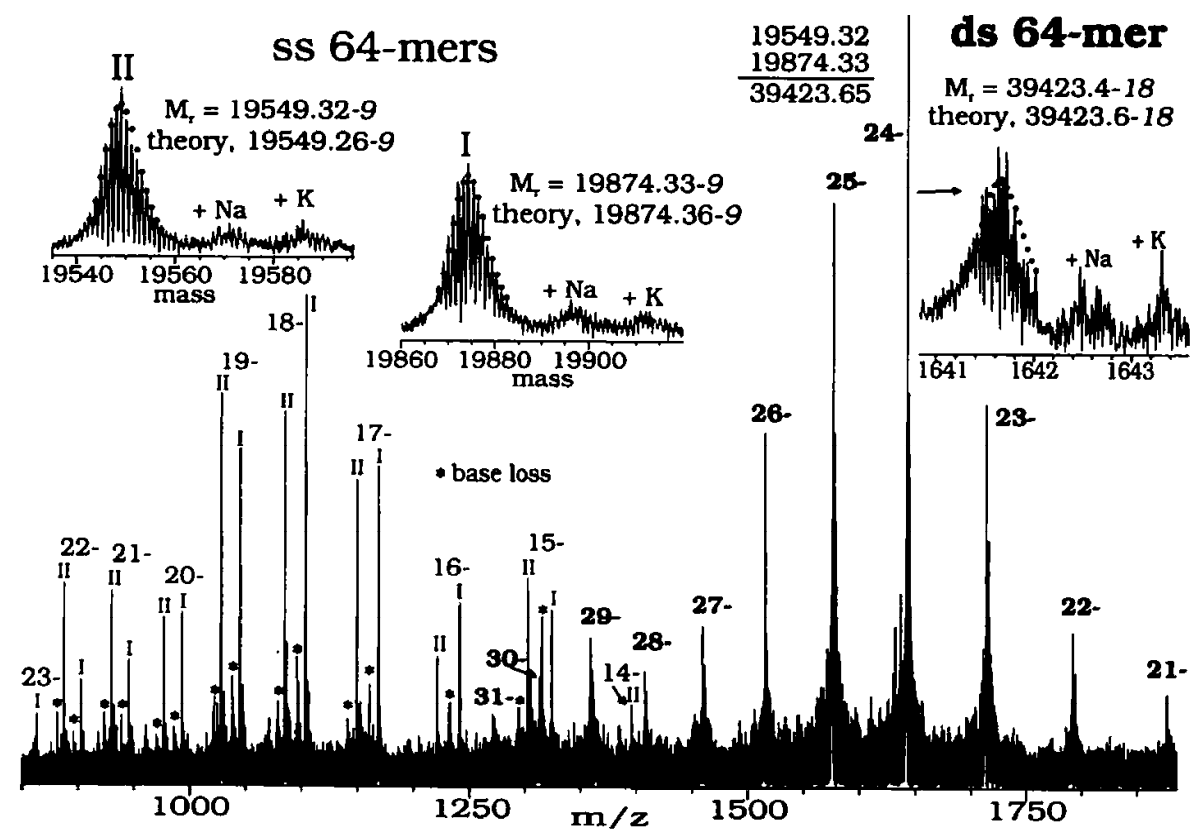

Figure 1. ESI/FTMS spectrum (10 scans) of ds 64-mer, ds charge states in bold. *: neutral adenine loss. Insets: isotopic peaks (ss charge states combined by deconvolution), with solid circles as the best fit of the predicted isotopic abundances $[11,21]$.
In contrast, the complementary bases (here designated as I and II) have large mass differences: $\mathbf{A}-\mathbf{T}$ $=9.0116 \mathrm{Da}$ and $\mathrm{G}-\mathrm{C}=40.0062 \mathrm{Da}$. Switching a $\mathrm{G}_{1} \mathrm{C}_{\mathrm{II}}$ pair to $\mathrm{G}_{\mathrm{II}} \mathrm{C}_{\mathrm{I}}\left(\Delta \mathrm{g}_{\mathrm{I}}=-1=-\Delta \mathrm{c}_{\mathrm{I}}\right)$ causes complementary changes in the ss $M_{r}$ values of $\Delta_{1} M_{r}=$ -40 (larger ssDNA) and $\Delta_{\mathrm{II}} M_{r}=+40$. Thus, eq 2,

$$
40.01 c_{\mathrm{I}}-9.012 \mathrm{a}_{\mathrm{I}}=304.05 \mathrm{a}+329.05 \mathrm{c}-{ }_{\mathrm{I}} M_{\mathrm{r} 0}-61.96
$$

derived using these restrictions and ${ }_{\mathrm{I}} M_{r 0}=\mathrm{a}_{1} \mathbf{A}+t_{\mathrm{I}} \mathrm{T}$ $+c_{1} C+g_{1} G-61.96$, defines the possible ssI compositions; these can be calculated by exhaustive trials. Alternatively, after finding one consistent composition, the others possible within a defined $M_{r}$ error $\left(\Delta_{\mathrm{I}} M_{r}\right.$, $\Delta_{\text {II }} M_{r}$ ) can be derived by modifying eq 2 to use differential values to define $\Delta \mathrm{m}_{\mathrm{I}}$, the mass difference between the original and the new composition of ssI (eq 3; note that $\Delta c=$

$$
\Delta \mathrm{m}_{\mathrm{I}}=25.01 \Delta \mathrm{a}+\Delta_{\mathrm{I}} M_{\mathrm{r}}-9.012 \Delta \mathrm{a}_{\mathrm{I}}+40.01 \Delta \mathrm{c}_{\mathrm{I}}
$$

$-\Delta a$ ). The compositions possible from eq 3 for $\Delta_{\text {I,II }} M_{r}$ and $\Delta \mathrm{m}_{\mathrm{l}} \leq \sim 1 \mathrm{Da}$ are listed in Table 1.

\section{Alternative Compositions for $\Delta \mathrm{a}=\mathbf{0}$}

If all $\Delta \mathrm{m}_{r}$ values are correct, the minimum $\Delta \mathrm{m}_{\mathrm{I}}$ value is found for $\Delta \mathrm{a}_{1}=+40(-40)$ and $\Delta \mathrm{c}_{\mathrm{I}}=+9(-9)$ : $\Delta \mathrm{m}_{\mathrm{I}}=-(+) 360.48++(-) 360.09=-0.39 \mathrm{Da}(+0.39$ $\mathrm{Da})$; these compositions need not be considered if $\mathrm{a}=<40$. Also, $\Delta \mathrm{a}_{1}=+9(-9)$ and $\Delta \mathrm{c}_{1}=+2(-2)$ yield $\Delta \mathrm{m}_{\mathrm{I}}=-(+) 81.11++(-) 80.02=-1.09(+1.09)$ Da (Table 1). For $\Delta_{\mathrm{ds}} M_{r}=0$, but with compensating errors such as $\Delta_{\mathrm{I}} M_{r}=+1(-1)$ and $\Delta_{\mathrm{II}} M_{r}=-1(+1)$, unchanged composition values $\left(\Delta a_{I}=0\right.$, etc. $)$ in eq 3 yield corresponding inequalities, $\Delta \mathrm{m}_{\mathrm{I}}=+1(-1)$. In the same way, these $\Delta_{\mathrm{I}, \mathrm{II}} M_{\mathrm{r}}$ errors for $\Delta \mathrm{a}_{1}=+9(-9)$ and $\Delta \mathrm{c}_{1}=+2(-2)$ yield $\Delta \mathrm{m}_{\mathrm{l}}=-0.1(+0.1)$. Thus, summing all the values of rows 1 and 2 (Table 1) yields those of row 3. Many of these obvious combinations are omitted from Table 1 , as are $\Delta a_{I}=+31(-31)$, $\Delta c_{1}=+7(-7)$ and other $\Delta \mathrm{m}_{1}$ compositions possible for $\Delta \mathrm{a}_{\mathrm{I}}=>21$.

\begin{tabular}{|c|c|c|c|c|c|c|}
\hline$\Delta, M_{r}$ & $\Delta_{11} M_{r}$ & $\Delta_{a_{i}}$ & $\Delta t_{1}$ & $\Delta c_{1}$ & $\Delta g_{1}$ & $\Delta m_{1}^{b}$ \\
\hline 0 & 0 & $+9(-9)$ & $-9(+9)$ & $+2(-2)$ & $-2(+2)$ & $-1.1(+1.1)$ \\
\hline$+1(-1)$ & $-1(+1)$ & 0 & 0 & 0 & 0 & $+1.0(-1.0)$ \\
\hline$+1(-1)$ & $-1(+1)$ & $+9(-9)$ & $-9(+9)$ & $+2(-2)$ & $-2(+2)$ & $-0.1(+0.1)$ \\
\hline 0 & $-1(+1)$ & $-6(+6)$ & $+7(-7)$ & $-2(+2)$ & $+1(-1)$ & $-0.9(+0.9)$ \\
\hline$+1(-1)$ & 0 & $-7(+7)$ & $+6(-6)$ & $-1(+1)$ & $+2(-2)$ & $-0.9(+0.9)$ \\
\hline$-0.5(+0.5)$ & $-0.5(+0.5)$ & $-15(-16)$ & $+16(+15)$ & $-4(-3)$ & $+3(+4)$ & $-0.4(-0.4)$ \\
\hline$-1(+1)$ & $-1(+1)^{c}$ & $+1(-1)$ & $+1(-1)$ & $-1(+1)$ & $-1(+1)$ & $0.0(0.0)$ \\
\hline$-1(+1)$ & $-1(+1)^{c}$ & $+10(-10)$ & $-8(+8)$ & $+1(-1)$ & $-3(+3)$ & $-1.1(+1.1)$ \\
\hline
\end{tabular}

Table 1. Possible ssI composition changes vs. measurement errors for $\Delta \mathrm{a}_{\mathrm{I}}<22^{\mathrm{a}}$

Other possible compositions can be found by summing the values in two rows. ${ }^{b} \Delta m_{1}= \pm<1.1 \mathrm{Da} ; \Delta m_{\|}$value the same but of opposite sign. ${ }_{\text {ds }} M$, error $2 \mathrm{Da}$. 
$\Delta \mathbf{a}= \pm \mathbf{1}$

The error combination $\Delta_{\mathrm{I}} M_{r}=0, \Delta_{\mathrm{II}} M_{r}=-1(+1)$ yields the alternatives $\Delta \mathrm{a}_{\mathrm{I}}=-6(+6)$ and $\Delta \mathrm{c}_{\mathrm{I}}=$ $-2(+2), \Delta m_{1}=-0.9(+0.9)$. However, errors of $\Delta_{1} M_{r}$ $=-0.5(+0.5), \Delta_{\mathrm{II}} M_{r}=-0.5(+0.5)$ give $\Delta \mathrm{a}_{1}=$ $-15(-16), \Delta c_{1}=-4(-3)$, with $\Delta m_{1}=-0.4(-0.4)$. This composition change is also possible for $\Delta_{1} M_{r}=$ $-1(+1), \Delta_{\mathrm{II}} M_{r}=0(0), \Delta \mathrm{m}_{\mathrm{I}}=-0.8(+0.2)$, and $\Delta_{\mathrm{I}} M_{r}$ $=0(0), \Delta_{\mathrm{II}} M_{\mathrm{r}}=-1(+1), \Delta \mathrm{M}_{\mathrm{l}}=+0.2(-0.8)$ that can be derived from summing appropriate rows of Table 1.

$\Delta \mathbf{a}= \pm \mathbf{2}$

If both $\Delta_{\mathrm{I}} M_{r}$ and $\Delta_{11} M_{r}=-1(+1)$ (not possible if $\Delta_{\mathrm{ds}} M_{r}=<2 \mathrm{Da}$ ), as would result from a $-1(+1) \mathrm{Da}$ calibration error, changes of $\Delta a_{1}=+1(-1)$ and $\Delta c_{1}=$ $-1(+1)$ in eq 3 yield $\Delta \mathrm{m}_{1}=0.0 \mathrm{Da}$. Summing rows as above, an additional composition change of $\Delta \mathrm{a}_{1}=$ $+9(-9), \Delta c_{I}=+2(-2)$ yields the compositions $\Delta a_{I}$ $=-8(+8), \Delta c_{1}=-3(+3)$ with $\Delta m_{1}=+1.1(-1.1)$, and those of Table 1, row 8 .

\section{9 kDa dsDNA}

If the Figure 1 data were from an unknown, the only possible ssI composition (Table 2) for $\leq 0.5 \mathrm{Da}$ errors in the $M_{r}$ values and $\Delta \mathrm{m}_{1}$ is $\mathrm{A}_{17} \mathrm{~T}_{12} \mathrm{C}_{14} \mathrm{G}_{21}$ (correct; ssII $\mathrm{A}_{12} \mathrm{~T}_{17} \mathrm{C}_{21} \mathrm{G}_{14}$ ). Increasing $\Delta_{\mathrm{ds}} M_{\mathrm{r}}$ to $1 \mathrm{Da}$ makes $\mathrm{A}_{2} \mathrm{~T}_{28} \mathrm{C}_{10} \mathrm{G}_{24}$ and $\mathrm{A}_{1} \mathrm{~T}_{27} \mathrm{C}_{11} \mathrm{G}_{25}$ possible, while this larger error for $\Delta_{1, \text { Il }} M_{r}$ also makes the compositions of $\Delta \mathrm{a}= \pm \sim 9$ possible with $\Delta \mathrm{m}<0.2 \mathrm{Da}$. If all errors, including $\Delta \mathrm{m}_{1}$, are $\sim 1 \mathrm{Da}$, the compositions of $\Delta \mathrm{a}_{\mathrm{I}}$ $= \pm 6-10$ are possible, such as $A_{8} T_{21} C_{12} G_{23}$ and $A_{23} T_{5} C_{16} G_{20}$. Ancillary data could distinguish such substantially different compositions. For example, in FT MS/MS spectra the mass accuracies for internal fragment ions containing one and two bases are sufficient to assign base compositions unequivocally [9]. Averaging these fragment ion compositions for the MS/MS spectrum of ssI (ssII) gave $\mathrm{A}_{12} \mathrm{~T}_{14} \mathrm{C}_{15} \mathrm{G}_{23}$ $\left(A_{8} T_{21} C_{22} G_{13}\right)$; because base $A$ is much more (see Figure 1) easily lost in fragmentation, and $T$ much less [ 1 , $7,9]$, these compositions support the correct assignments $A_{17} T_{12} C_{14} G_{21}\left(A_{12} T_{17} C_{21} G_{14}\right)$. Compositions with single base variations, such as $A_{18} T_{13} C_{13} G_{20}$, are only possible for same sign $1 \mathrm{Da}$ errors in ${ }_{\mathrm{I}} M_{r}$ and ${ }_{\mathrm{II}} M_{r}$ that give a $2 \mathrm{Da}$ error in $\mathrm{ds}_{\mathrm{s}} M_{r}$.

\section{0 kDa dsDNA [5]}

ESI/MS of this PCR-prepared sample ( 45 base pairs plus $5^{\prime}-\mathrm{A}_{2} \mathrm{~T}_{2}$ on each ss) gave no ds molecular ions, but the ss ions (isotopically unresolved) yielded $M_{r}$ values of 15275.2 and 15029.0 (theory 15276.0 and 15029.7). If the ${ }_{\mathrm{ss}} M_{r}$ and $\Delta \mathrm{m}$ errors had been instead $\leq 0.5 \mathrm{Da}$, the only possible composition from eq 2 (accounting for 5'-phosphorylation) is the correct one, $\mathrm{A}_{23} \mathrm{~T}_{9} \mathrm{C}_{7} \mathrm{G}_{10}$ using 15275.7 and 15029.5. For $\leq 1 \mathrm{Da}$ assumed errors, $\mathrm{A}_{24} \mathrm{~T}_{10} \mathrm{C}_{6} \mathrm{G}_{9}$ (actual errors $\Delta_{1} M_{r}=$ $\left.-1.3, \Delta_{\mathrm{II}} M_{\mathrm{r}}=-1.2\right), \mathrm{A}_{8} \mathrm{~T}_{25} \mathrm{C}_{3} \mathrm{G}_{13}, \mathrm{~A}_{15} \mathrm{~T}_{19} \mathrm{C}_{4} \mathrm{G}_{11}$, and $A_{32} \mathrm{~T}_{0} \mathrm{C}_{9} \mathrm{G}_{8}$, plus those very similar (Table 1 , row 7 ) to the last three, are possible.

Table 2. Possible ssI compositions from measured $M$, values ${ }^{\mathrm{a}}$

\begin{tabular}{|c|c|c|c|c|c|c|}
\hline$\Delta_{1} M, \Delta_{\|} M_{r}$ & $a_{1}$ & $t_{1}$ & $c_{1}$ & $g_{1}$ & $\Delta m_{1}$ & $\Delta m_{11}$ \\
\hline \multicolumn{7}{|c|}{$19874.33-9,19549.32-9 ;$ actual errors $-0.03,+0.06$} \\
\hline $0.0,0.0$ & 17 & 12 & 14 & $21^{b}$ & -0.03 & +0.06 \\
\hline$+1.0,-1.0$ & 26 & 3 & 16 & 19 & -0.12 & +0.16 \\
\hline$-1.0+1.0$ & 8 & 21 & 12 & 23 & +0.07 & -0.03 \\
\hline$+1.0,0.0$ & 10 & 18 & 13 & 23 & -0.96 & +1.00 \\
\hline $0.0+1.0$ & 23 & 5 & 16 & 20 & +0.91 & -0.86 \\
\hline$-0.5,-0.5$ & 2 & 28 & 10 & 24 & -0.37 & +0.40 \\
\hline$-1.0,-1.0^{c}$ & 18 & 13 & 13 & 20 & -0.03 & +0.06 \\
\hline \multicolumn{7}{|c|}{$15275.2,15039.0 ;^{\mathrm{d}}$ actual errors $-0.8,-0.7$} \\
\hline $0.0,0.0$ & 8 & 25 & 3 & 13 & -0.5 & +0.2 \\
\hline$+0.5,+0.5$ & 23 & 9 & 7 & 10 & -0.2 & -0.1 \\
\hline$-0.5,-0.5$ & 24 & 10 & 6 & 9 & -0.2 & -0.1 \\
\hline$+1.0,0.0$ & 32 & 0 & 9 & 8 & -0.8 & +0.5 \\
\hline$-1.0,0.0$ & 15 & 19 & 4 & 11 & +0.4 & -0.7 \\
\hline$-1.0,-1.0^{c}$ & 9 & 26 & 2 & 12 & -0.5 & +0.2 \\
\hline \multicolumn{7}{|c|}{6410,$5827 ;{ }^{\text {de }}$ actual errors $-0.2,+0.2$} \\
\hline $0.0,0.0$ & 7 & 0 & 0 & 13 & 0 & 0 \\
\hline $0.0,0.0$ & 6 & 1 & 0 & 13 & +9 & -9 \\
\hline$+0.5,+0.5$ & 4 & 2 & 0 & 14 & +2 & -2 \\
\hline$+1.0,+1.0^{c}$ & 2 & 3 & 0 & 15 & -4 & +4 \\
\hline
\end{tabular}

${ }^{3}$ Other possibilities of very similar composition can be derived from Table 1 , such as the effect of reversing the,+- signs of the first two columns. ${ }^{C}$ Correct compositions in italics. ${ }^{c}{ }_{d s} M_{r}$ error $2 \mathrm{Da}$. ${ }^{d}$ Isotopically averaged $M_{r}$ values $\left(M_{r a}\right) ; M_{r o}=0.99952 M_{r a}$ for nucleotides [22]. - Possible compositions for $\Delta m=<15$. 


\section{2 kDa dsDNA}

In a pioneering example [3], ESI/MS of a 20 base pair dsDNA of $M_{r}=12237$ (measured 12297) gave ${ }_{\text {ss }} M_{r}$ values of $6410 \pm 2$ and $5827 \pm 2$ (theory $6410.2,5826.8$ ). Here, the smaller size and absence of two bases greatly limits the possible compositions; the correct one (ssI, $A_{7} G_{13}$ ) is favored (Table 2).

\section{Conclusions}

For the $\leq 0.5 \mathrm{Da}$ errors of $M_{r}$ achievable for dsDNA as large as $39 \mathrm{kDa}$ (Figure 1), the possible mass values restrict the ssI and ssII compositions to only the correct assignments (Table 1). For $1 \mathrm{Da}$ errors in ${ }_{1,11} M_{r}$, but $\Delta_{\mathrm{ds}} M_{r}=2$, one alternative composition differs by only one in each base value, and $\Delta a$ and $\Delta t$ are $\geq 6$ for all others; the elimination of such variant possibilities by MS/MS is under further investigation. ESI/FTMS can provide accurate $M_{r}$ values even of proteins in complex mixtures $[14,15]$; such characterization of unseparated restriction enzyme products from larger DNA should be of special importance with the increasingly widespread use of PCR for trace DNA amplification.

\section{Acknowledgments}

The authors thank Z. Guan, G. A. Valaskovic, and E. K. Fridriksson for valuable advice and assistance, $T$. W. Thannhauser for DNA synthesis and purification, and the National Institutes of Health (Grant No. GM16609; NLK, Cell \& Molecular Biology training Grant 08-T2GM07273) for financial support.

\section{References}

1. McLuckey, S. A.; Habibi-Goudarzi, S. J. Am. Chem. Soc. 1993, 115, 12085-12095.

2. Pomerantz, S. C.; Kowalak, J. A.; McCloskey, J. A. J. Am. Soc. Mass Spectrom. 1993, 4, 204-209.

3. Light-Wahl, K. J.; Springer, D. L.; Winger, B. E.; Edmonds, C. G.; Camp, D. G., II; Thrall, B. D.; Smith, R. D. J. Am. Chem. Soc. 1993, 115, 803-804.

4. Ganem, B.; Li, Y.-T.; Henion, J. D. Tetrahedron Lett. 1993, 34, 1445-1448. Potier, N.; Van Dorsselaer, A.; Cordier, Y.; Roch, O.; Bischoff, R. Nucleic Acids Res. 1994, 22, 3895-3903. Gale, D. C.; Goodlett, D. R.; Light-Wahl, K. J.; Smith, R. D. I. Am. Chem. Soc. 1994, 116, 6027-6028. Doktycz, M. J.; HabibiGoudarzi, S.; McLuckey, S. A. Anal. Chem. 1994, 66, 3416-3422. Ding, J.; Anderegg, R. J. J. Am. Soc. Mass Spectrom. 1995, 6, 159-164. Doktycz, M. J.; Hurst, G. B.; HabibiGoudarzi, S.; McLuckey, S. A.; Tang, K.; Chen, C. H.; Uzeil, M.; Jacobson, K. B.; Woychik, R. P.; Buchanan, M. V. Anal. Biochem. 1995, 230, 205-214.

5. Naito, Y.; Ishikawa, K.; Koga, Y.; Tsuneyoshi, T.; Terunuma,
H.; Arakawa, R. Rapid Commun. Mass Spectrom. 1995, 9, 1484-1486.

6. Wunschel, D. S.; Fox, K. F.; Fox, A.; Bruce, J. E.; Muddiman, D. C.; Smith, R. D. Rapid Commun. Mass Spectrom. 1996, 10 , 29-35.

7. Little, D. P.; Chorush, R. A.; Speir, J. P.; Senko, M. W.; Kelleher, N. L.; McLafferty, F. W. I. Am. Chem. Soc. 1994, 116, 4893-4897.

8. Chen, R.; Cheng, X.; Mitchell, D. W.; Hofstadler, S. A.; Wu, Q.; Rockwood, A. L.; Sherman, M. G.; Smith, R. D. Anal. Chem. 1995, 67, 1159-1163.

9. Little, D. P.; McLafferty, F. W. J. Am. Chem. Soc. 1995, 117, 6783-6784. Little, D. P.; Aaserud, D. J.; Valaskovic, G. A.; McLafferty, F. W. I. Am. Chem. Soc. 1996, 118, 9352-9359.

10. Little, D. P.; Thannhauser, T. W.; McLafferty, F. W. Proc. Natl. Acad. Sci. USA 1995, 92, 2318-2322.

11. Beu, S. C.; Senko, M. W.; Quinn, J. P.; Wampler, F. M. III; McLafferty, F. W. I. Am. Soc. Mass Spectrom. 1993, 4, 557-565. McLafferty, F. W. Acc. Chem. Res. 1994, 27, 379-386.

12. Clegg, G. A.; Dole, M. Biopolymers 1971, 10, 821-826. Fenn, J. B.; Mann, M.; Meng, C. K.; Wong, S. F.; Whitehouse, C. M. Science 1989, 246, 64-71.

13. Marshall, A. G.; Comisarow, M. B. Chem. Phys. Lett. 1974, 25, 282-283. Marshall, A. G.; Grosshans, P. B. Anal. Chem. 1991 63, 215A-229A.

14. Wood, T. D.; Chen, L. H.; Kelleher, N. L.; Little, D. P.; Kenyon, G. L.; McLafferty, F. W. Biochemistry 1995, 34, 16251-16254.

15. Kelleher, N. L.; Costello, C. A.; Begley, T. P.; McLafferty, F. W. J. Am. Soc. Mass Spectrom. 1995, 6, 981-984.

16. Speir, J. P.; Senko, M. W.; Little, D. P.; Loo, J. A.; McLafferty, F. W. I. Mass Spectrom. 1995, 30, 39-42.

17. The 64-mer CTGGCACGACAGGTTTCCCGACTGGAAAGCGGGCAGTGAGCGCAACGCAATTAATGTGAGTTAG (ssI) and its complement synthesized by the Comell Peptide/DNA Synthesis Facility were annealed in aqueous 5 $\mathrm{mM}$ piperidine solution at $95^{\circ} \mathrm{C}$ for $5 \mathrm{~min}$, slowly cooled to $25^{\circ} \mathrm{C}$, and diluted to $5 \mu \mathrm{M}$ in $3: 1 \mathrm{CH}_{3} \mathrm{CN}: \mathrm{H}_{2} \mathrm{O}(2.5 \mathrm{mM}$ in piperidine) [18]. This solution was introduced at $1 \mu \mathrm{L} / \mathrm{min}$ into a previously described 6 T ESI/FTMS system [11], with noncovalent ion adducts minimized by $20 \mathrm{~ms}$ of infrared photodissociation (25 W Synrad $\mathrm{CO}_{2}$ laser, 35\% duty cycle) [19].

18. Greig, M.; Griffey, R. H. Rapid Commun. Mass Spectrom. 1995, 9, 97-102.

19. Little, D. P.; McLafferty, F. W. I. Am. Soc. Mass Spectrom. 1996, 7, 209-210.

20. Here, $M$, is the mass of the most abundant isotopic peak, which differs by $<20 \mathrm{ppm}$ from the $M_{r}$ value based on natural isotopic abundances. Variations in the latter affect only the abundance, not the mass, of an isotopic peak [11]. The number of ${ }^{13} \mathrm{C}$ atoms, $n$, in the most abundant isotopic peak is given in italics following the mass value: $M_{r 0}=M_{r}$ - n(1.0034).

21. Senko, M. W.; Beu, S. C.; McLafferty, F. W. J. Am. Soc. Mass Spectrom. 1995, 6, 229-233.

22. Zubarev, R. A.; Bondarenko, P. V. Rapid Commun. Mass Spectrom. 1991, 5, 276-277. 